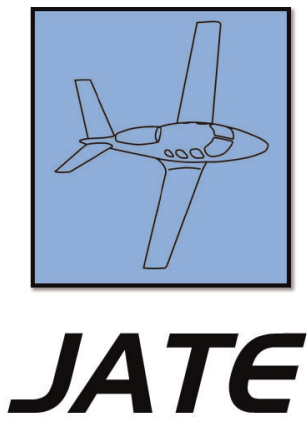

Journal of Aviation Technology and Engineering 6:1 (2016) 44-52

\title{
Accident Rates, Phase of Operations, and Injury Severity for Solo Students in Pursuit of Private Pilot Certification (1994-2013)
}

\author{
Douglas Boyd \\ University of Texas Graduate School of Biomedical Sciences at Houston
}

Peter Dittmer

Eastern New Mexico University

\begin{abstract}
Flight training accidents constitute $14 \%$ of general aviation accidents. Herein we determined the rates, injury severity, and phase of flight for primary student solo accidents/incidents (mishaps) in Cessna 172 aircraft.

Mishaps over the period spanning 1994-2013 were identified from the NTSB database. Student population data were from the FAA. Statistics employed proportion tests, Poisson distribution, and Mann-Whitney tests.

Across the study period, 598 mishaps were identified. While the mishap rate increased nearly two-fold between 1994/1997 and 2002/ 2005, a 35\% decline was evident thereafter. Nevertheless, no statistical difference in mishap rates was evident between the initial and current periods. Over $90 \%$ of mishaps resulted in no or minor injuries. However, $97 \%$ of involved aircraft incurred substantial damage and no incidents were reported. While the percentage of takeoff accidents climbed two-fold, landing accidents accounted for $>70 \%$ of all mishaps and remained unchanged over the 20 years. Over one-third of landing accidents were related to excess speed. Landing speed computation for a solo flight with an average weight trainee indicated an 11 knot lower V-ref than that for a Cessna $172 \mathrm{~S}$ at maximum weight. No statistical difference was evident between the two genders for most phases of operation, although females were overrepresented for excess speed landing accidents.

Landing accidents, one-third of which relate to excess speed, continue to challenge primary students. The importance of landing speed control, in the context of reduced aircraft weight, should receive additional emphasis in flight instruction.
\end{abstract}

Keywords: flight instruction, aviation accidents, student pilots, flight training

\section{Introduction}

General aviation includes all civilian aviation apart from operations involving paid passenger transport and is regulated by a set of FAA rules (14CFR Part 91) that govern the operation of small, noncommercial aircraft within the United States (Electronic Code of Federal Regulation, 2015a). Although accidents for the airlines, which operate under a more stringent 
set of regulations-14CFR Part 121-have dramatically declined over the last two decades, only a minimal decrease has been evident for general aviation (DeJohn, Webster, \& Larcher, 2013; Li \& Baker, 2007). Indeed, this latter sector of aviation accounts for the overwhelming majority (94\%) of civil aviation fatalities in the United States (Li \& Baker, 2007).

Historically, $14 \%$ of general aviation accidents occur during training, inclusive of primary, advanced instruction and proficiency checks (Baker, Lamb, \& Dodd, 1996). However, to date, relatively little peer-reviewed research has been undertaken in regard to these types of mishaps (Baker et al., 1996; Uitdewilligen \& de Voogt, 2009). In pioneering work, Baker and colleagues (1996) studied 638 instructional flight accidents occurring for the years 1989 and 1991 in fixed-wing, powered aircraft. These investigators determined that $30 \%$ of the accidents involving solo students undertaking primary training (flight instruction for the most basic airman certificate-private pilot) were in the landing phase (Baker et al., 1996). These data were in contrast to a more recent study (Uitdewilligen \& de Voogt, 2009) that reported that of all accidents by primary student pilots flying solo, $64 \%$ were in this phase of operation. Perhaps not surprisingly, the majority of accidents (86\%) were deemed to be skill base-related (Uitdewilligen \& de Voogt, 2009). In addition to the peer-reviewed research, a comprehensive study performed by the Air Safety Institute of instructional accidents also reported that across their study period (2002-2011) nearly two-thirds of accidents involving solo students in fixed-wing aircraft occurred in the landing phase (Kenny, 2014).

Notwithstanding the aforementioned contributions, there are still several gaps in knowledge regarding flight training accidents. Temporal shifts in accident causes had not been studied prior. Changes in training strategies over time (Federal Aviation Administration, 2016) may potentially lead to a decrease or increase in accidents for a particular phase of flight. Such data could inform where current training should be emphasized. In addition, the prior studies were not without limitations. For example, earlier studies either excluded (Kenny, 2014) incidents from their analysis or were ambiguous (Baker et al., 1996; Uitdewilligen \& de Voogt, 2009) as to whether this event category was included. Incidents are defined as an occurrence, other than an accident, which affects the operation of an aircraft or could affect the safety of operations (Electronic Code of Federal Regulation, 2010). This is important since the NTSB categorizes an accident as one in which there is either a serious/fatal occupant injury or in which the aircraft is substantially damaged (Electronic Code of Federal Regulation, 2010). Landing accidents are rarely fatal (Uitdewilligen \& de Voogt, 2009), raising the possibility that events with damage other than substantial (and therefore categorized as an incident) may have been excluded in prior analyses.
With these considerations in mind, the objectives of the current study were to determine the rates, injury severity, phase of flight, and temporal changes for primary student accidents/incidents (herein collectively referred to as mishaps) in Cessna 172 aircraft and for which the trainee was on a solo flight. Accidents with solo students represent approximately $67 \%$ of all primary training accidents (Kenny, 2014). This study focused on Cessna 172 aircraft as it is a popular choice for primary flight training (Cessna, 2015). We elected to limit our study to mishaps incurred by students on solo flights for multiple reasons: (a) for dual flights, student error cannot be unambiguously ascribed to gaps in skills/knowledge of the trainee; (b) for some events it is difficult to determine at which point the Certified Flight Instructor (CFI) assumed aircraft control; (c) with few exceptions, for dual flights, the NTSB accident report cites CFI flight time rather than that for the student.

\section{Methods}

\section{Query Strategy}

Data were from the publicly available NTSB aviation accident Microsoft Access database (2015 December release) that, despite its name, includes both accident and incident reports (National Transportation Safety Board, 2015a). The database was queried for accidents/incidents occurring during the period spanning 1994-2013 involving a solo student (pursuing private pilot certification) operating a Cessna 172 aircraft under 14CFR Part 91 regulations. The researchers did not query beyond 2013 since an NTSB accident investigation takes an average of 13 months to complete (Fielding, Lo, \& Yang, 2011). Data were exported to Excel, checked for duplicates (which were deleted), and manually inspected to restrict accidents to those in which the trainee was solo. Mishaps that were maintenance/ mechanical-related, due to suicide, or for which the cause was undetermined were excluded.

Since the FAA does not track annual primary flight training time, the number of student starts defined as new trainees, annually, was employed as denominator (population at risk) for the current study. This parameter is based on student certification by the FAA, the latter mandatory for solo operations. Data for 2001-2013 were obtained from the FAA General Aviation and Part 135 Activity Surveys (Federal Aviation Administration, 2015). The comparable pre-2001 data was kindly provided by Brad Wacker at the FAA. However, since the FAA increased the duration of validity for student certificates for applicants under 40 years of age from 36 to 60 months in 2010, the number of student starts for $2010-2013$ was determined by linear regression $\left(r^{2}=0.99\right)$ using starts for the prior three time periods. 
Phases of Flight Operations and Operational Definition of Excess Speed

Demarcation of the various phases of flight was as follows. A climb of an ascending aircraft was distinguished from a takeoff based on aircraft locationoutside or within the airport lateral limits, respectively. The approach phase was defined as a descending aircraft located at or below the traffic pattern altitude and beyond the lateral limits of the airport. A landing used the same criteria as approach with the exception that the aircraft was within the lateral limits of the airport. A descent was distinguished from the approach phase in that the former was at an altitude in excess of the traffic pattern altitude for the airport. Taxiing was defined as off- runway movement of the aircraft.

Excess speed for landing accidents was operationally defined as either of the following occurring: (i) the NTSB report citing high speed in its probable cause; (ii) the aircraft "porpoising" on landing; (iii) multiple bounces of the landing airplane; (iv) the landing roll exceeding the length of the runway. These latter parameters were chosen on the basis of the physics of increased kinetic energy associated with extra landing airspeed (Federal Aviation Administration, 2008; Flight Safety Foundation-Flight Safety Digest, 2000). Conversely, a low speed for landing was defined as an aerodynamic stall onto the landing runway per the NTSB report. It should be noted that an aircraft experiencing an aerodynamic stall due to flaring too high was excluded from our definition of low landing speed. Appropriate speed represented an exclusion category used for the remaining cases.

\section{Injury Severity}

Injury severity (none, minor, serious, fatal) and aircraft damage (none, minor, substantial, destroyed) were per the NTSB reports (Electronic Code of Federal Regulation, 2010; National Transportation Safety Board, 2015b).

\section{Determination of Reference Landing Speed (V-ref) for a Cessna 172S Aircraft at Less Than Maximum Weight}

Basic empty and maximum certified ramp weights for the Cessna $172 \mathrm{~S}$ were per the pilot operating handbook (POH). The body mass for a student pilot $(181.5 \mathrm{lbs}$.) represented the mathematically weight-adjusted mean of the non-institutionalized United States population (age $\geq 16$ years) computed using data from the National Health and Nutrition Examination Survey (NHANES) for the 20132014 period (Centers for Disease Control and Prevention, 2015 ; 2016). Aerodynamic stall speed $\left(\mathrm{V}_{\mathrm{SO}}\right)$ for a Cessna C172S with flaps fully extended for operations with a solo occupant of average national weight was determined with the equation below (Clancy, 1978). Calibrated (kcas) airspeed in knots was converted to indicated airspeed (kias) by referencing the $\mathrm{C} 172 \mathrm{~S} \mathrm{POH}$.

$$
\begin{aligned}
& \text { Vso for Solo Flight }=\text { Vso at Maximum Weight } X \\
& \qquad \sqrt{\frac{\text { Aircraft Weight Solo Flight }}{\text { Maximum Certified Aircraft Weight }}}:
\end{aligned}
$$

\section{Statistics}

Proportion tests employed the Pearson chi-square statistic except where the expected count was less than 5, whereby Fisher's Exact Test was used (Agresti, 2012; Field, 2009) to determine if there was an overall difference in proportions. $P$-values for cells in multi-nomial tables were derived from adjusted standardized residuals (Z-scores) in post-hoc testing. To determine whether the rate of trainee accidents changed over time, a generalized linear model with Poisson distribution (Dobson \& Barnett, 2008) was employed using the natural $\log$ of the number of student starts as an offset. Statistical comparison of trainee flight time (single engine) and age between the two genders was determined using a Mann-Whitney test (Field, 2009) as normality analysis indicated a non-Gaussian distributed population (ShapiroWilk $p<0.001$ ) (Field, 2009) for both genders and for both parameters. IBM SPSS (v 23) software was used for all statistical analyses. For all analyses, a $p$ value of $<0.05$ was considered statistically significant.

\section{Results}

\section{Study Population}

Data resulting from a query of the NTSB database for mishaps (collectively used to include both accidents and incidents) involving primary students soloing in Cessna 172 aircraft for the period spanning 1994-2013 returned 598 records and is illustrated in Table 1. Age and flight time data categorized by gender were available for a subset of these accidents (Table 1). The median age of the male student population was significantly $(p=0.04)$ higher than that for females. Conversely, female trainees accrued 14 hours more flight time than male students engaged in primary instruction $(p=0.05)$.

\section{Temporal Change in Trainee Mishap Rates}

With the adoption of new approaches in flight instruction (e.g. scenario-based training, the FAA Flight Industry Training Standards [Federal Aviation Administration, 2016]) over the last two decades and per one of the objectives of the current study, we determined whether accident/incident rates have changed over time. Surprisingly, adjusting for variations in student starts across the two decades, the mishap rate 
increased steadily from 26 per 100,000 trainees for the initial period (1994-1997), peaking at 45 (per 100,000 students) for the 2002-2005 time frame (Figure 1A). Rate analysis with a Poisson distribution revealed this increase to be statistically significant $(p<0.001)$. Thereafter, a decline in the rate of accidents/incidents was evident with a $35 \%$ reduction $(p=$ 0.001 ) witnessed between the 2002-2005 period and the most recent period (2010-2013). However, comparing the initial and most current periods revealed no statistical difference in mishap rates $(p=0.451)$.

We next determined whether injury severity changed over time as described in the objectives of the study. For increased statistical power, three aggregate time periods were used. The overwhelming majority (93\%) of mishaps for the earliest period resulted in occupants receiving no or only minor injuries (Figure 1B). Furthermore, we found little evidence of change in injury severity over the subsequent periods (Figure 1B) as evident in contingency table analysis $\left(\chi^{2}=p=0.404\right)$.

Aircraft damage data were available from 1999 forward. Interestingly, of 477 mishaps, $97.7 \%$ and $2.1 \%$ of the involved aircraft were classified as incurring substantial damage or were destroyed, respectively (Table 2). Somewhat surprisingly, there were no incidents reported across the entire study cohort.

\section{Categorization of Accidents by Phase of Flight}

Categorizing aviation accidents by phase of flight could inform where training has been successful and conversely areas of instruction that warrant further emphasis. This goal represented an objective of the current study.

Where there were a small number of events, we aggregated phases of operations for increased statistical power. Interestingly, for the earliest period (1994-2000), climb/ cruise/maneuvering/descent operations accounted for $8.2 \%$ of all accidents (Figure 2) and a steady decline in the percentage of accidents in these flight phases was evident thereafter $(4.5 \%$ and $1.4 \%$ for 2001-2007 and the 20082013 periods, respectively). An underrepresentation of accidents for these aggregated phases of operations was evident for the most recent period $(p=0.021)$. Conversely, while accidents during takeoff accounted for $8.2 \%$ of accidents for the 1994-2000 period, this percentage climbed subsequently $(15.8 \%, 16.2 \%)$. Indeed, there were disproportionately fewer accidents for the initial period relative to later periods $(p=0.009)$. However, most
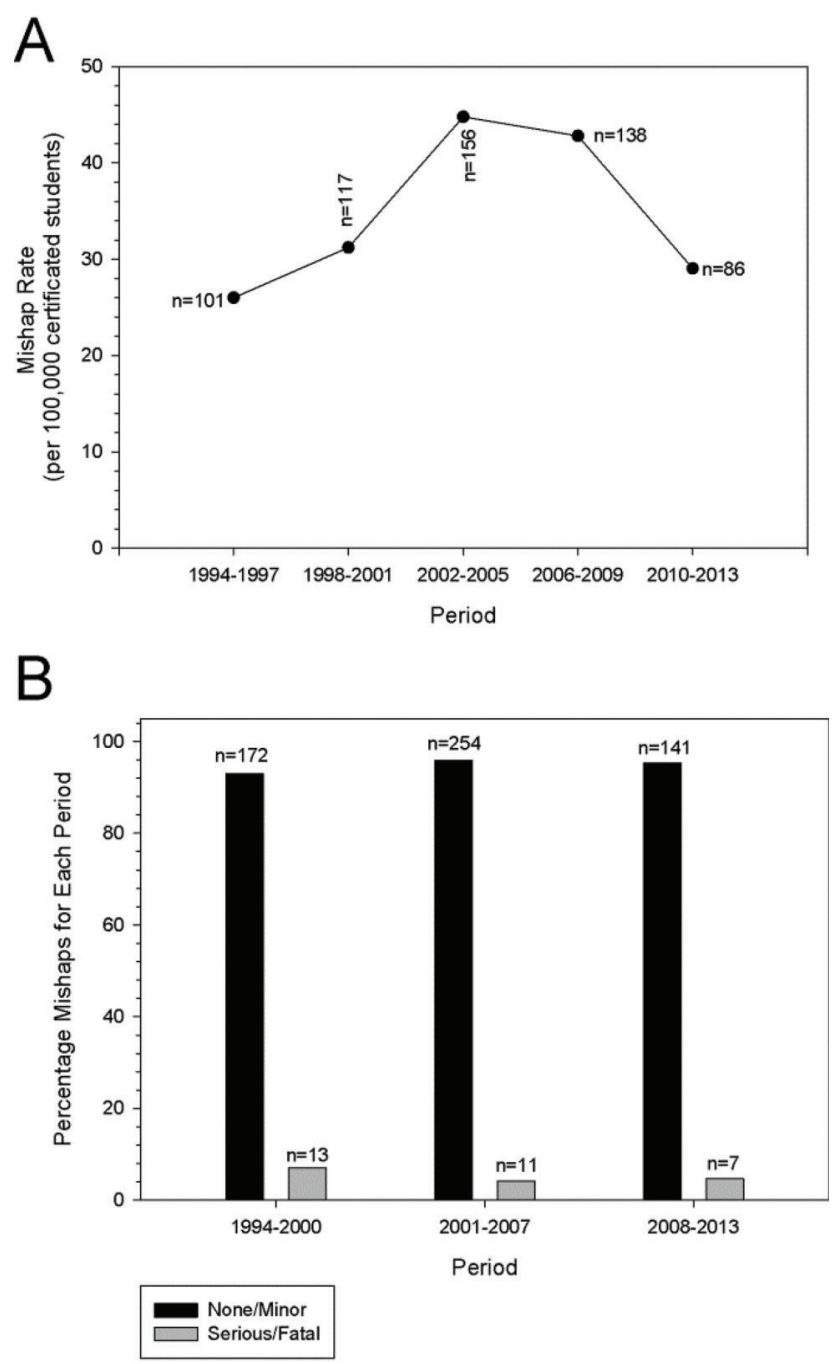

Figure 1. Temporal trends in mishap rate and injury severity. Panel A. The mishap rate normalized to the total number of primary students for the corresponding period is illustrated; $\mathrm{n}$, mishap count for the indicated period. Panel B. Mishaps were categorized according to injury severity and expressed as a percentage of the total for the indicated period; n, mishap count for the corresponding period.

Table 1.

Population cohort.

\begin{tabular}{lccccc}
\hline & Gender & Count $(\boldsymbol{n})$ & Median & Statistic & P-Value \\
\hline All Mishaps & All & 598 & N/A & N/A & N/A \\
Age (Years) & Male & 441 & 38 & Mann-Whitney & 0.04 \\
Flight Time (Hours) & Female & 48 & 30 & & Mann-Whitney \\
& Male & 283 & 38 & 5.05 \\
\hline
\end{tabular}

The study cohort is described. Tests of normality for both age and flight time (Shapiro-Wilk) indicated a non-Gaussian distribution. Accordingly, a nonparametric test (Mann-Whitney) was used to test for statistical significance. The sum of $n$ for both genders for each parameter (age, flight time) is less than the count for all mishaps due to missing data. N/A, not applicable. 
Table 2.

Aircraft damage.

\begin{tabular}{lcc}
\hline $\begin{array}{l}\text { Aircraft Damage } \\
\text { Category }\end{array}$ & n & \% \\
\hline None & 1 & 0.2 \\
Minor & 0 & 0.0 \\
Substantial & 466 & 97.7 \\
Destroyed & 10 & 2.1 \\
TOTAL & 477 & 100 \\
\hline
\end{tabular}

Aircraft damage was per the NTSB report. The NTSB database did not include aircraft damage data prior to 1999 so the data herein reflect counts for the 1999-2013 period.

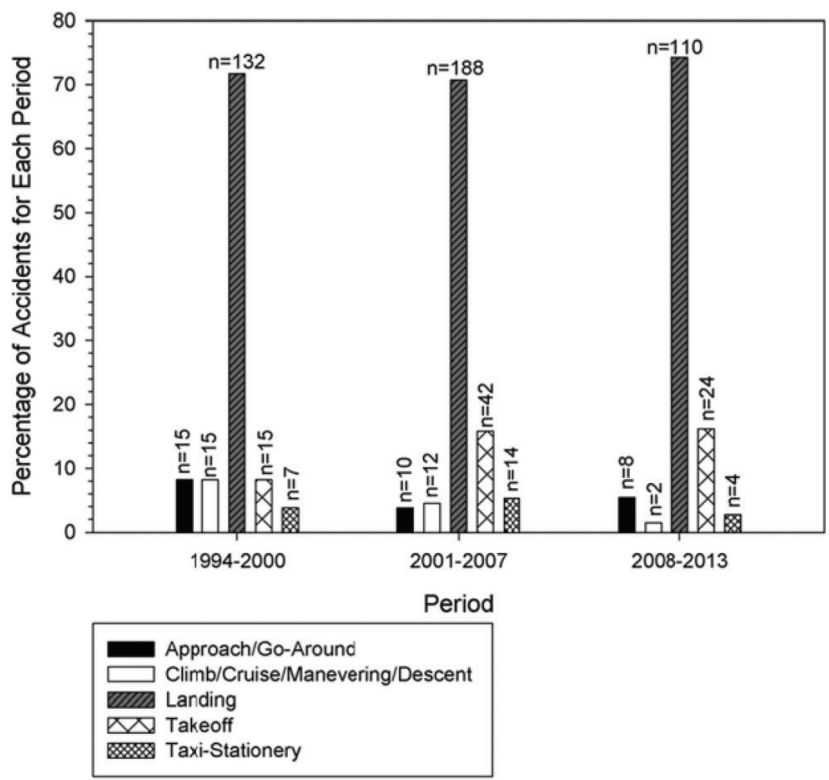

Figure 2. Temporal change in accidents based on phase of operation. Accidents, for which phase of flight data were available, were divided into three time periods. The number of accidents for each phase of flight is expressed as a percentage of all accidents for the indicated period. A contingency table demonstrated $\left(\chi^{2} p=0.014\right)$ a statistical difference in proportions between each of the three periods. Z-values were used to derive $p$ values in post-hoc testing to determine the contribution of individual cells to the overall statistical significance in proportions; $\mathrm{n}$, accident count.

importantly by far, the largest category of accidents was in the landing phase, which accounted for in excess of $70 \%$ for each of the three time frames. Furthermore, no change in the proportion of these accidents was evident across the three periods. These data would suggest that students continue to struggle with this phase of operation.

\section{Mis-Speed Landing Accidents}

The high proportion of landing accidents prompted an exploration of factors that might contribute to these types of mishaps. Certainly, a prior study cited deficiency in the flaring technique (also known as round-out) as one of the causes of landing accidents for students (Benbassat \&
Abramson, 2002b). Manual inspection of accident reports in the current study revealed a preponderance of "high speed" landings as evidenced by the NTSB, citing either an excessive approach speed, porpoising, multiple bounces, or exceeding the length of the landing runway in the probable cause section of their report. To further investigate the frequency of mis-speed landing accidents, occurrences were categorized as appropriate, excess, or low speed as described in the methods section of this paper. Interestingly, for each of the three periods, over one-third of the accidents were related to the student's excess landing speed (Figure 3A). In stark contrast, a low speed landing was a scarcity, accounting for only 2 of 153 mis-speed-related accidents. It should be noted that of the total number $(n=$ 153) of mis-speed accidents, gusting conditions were reported for only three. The proportions of accidents related to appropriate/excess/low speeds did not change $\left(\chi^{2} p=\right.$ $0.967)$ between the three periods. This would suggest that accidents related to landing with an excess speed represent a continuing issue regarding safe operations for this phase of flight by solo students. Somewhat surprisingly, gender analysis for these types of landing accidents indicated (Figure 3B) a disproportionately higher rate of mis-speed landing accidents with female students $\left(\chi^{2} p=0.010\right)$.

The above findings begged the question as to the reason(s) for students carrying excess speed during landing. The reference landing speed (V-ref) is a function of $\mathrm{V}_{\mathrm{SO}}\left(1.3 \mathrm{X} \mathrm{V}_{\mathrm{SO}}\right)$ (Federal Aviation Administration, 2008; Flight Safety Foundation-Flight Safety Digest, 2000) and the latter value varies with aircraft weight (Federal Aviation Administration, 2008). However the V-ref speed specified by the Cessna $172 \mathrm{~S} \mathrm{POH}$ is derived for an aircraft at its maximum certified weight $(2,550 \mathrm{lbs}$.). Considering these facts and that accident flights were with a single occupant, the V-ref speed recommended by the Cessna $172 \mathrm{~S} \mathrm{POH}$ (60-70 kias) was compared with that for aircraft with a single occupant. Indeed, using the assumptions of a solo student of average body mass (182 lbs., based on the noninstitutionalized US population) in a Cessna $172 \mathrm{~S}$ with 3 hours of fuel remaining the V-ref speed was determined to be at least 11 knots (indicated airspeed) lower than that specified in the $\mathrm{POH}$ (Table 3).

\section{Gender Differences for Accidents Based on Phase of Flight}

In view of the overrepresentation of females in misspeed landing accidents, we were also curious as to whether any other phase(s) of operation showed a disproportionate rate of accidents by either gender. Indeed, a reduced accident rate for females was apparent for the climb-cruisemaneuver-descent phases of flight (Figure 4), whereas the rate appeared higher for takeoff and taxi-standing operations. However, caution should be exercised in interpreting these data as no overall change (Fisher's Exact $p=0.227$ ) in proportions for the two genders was evident across the 
various phases of flight presumably due to the small number of events for some of the phases of operations.
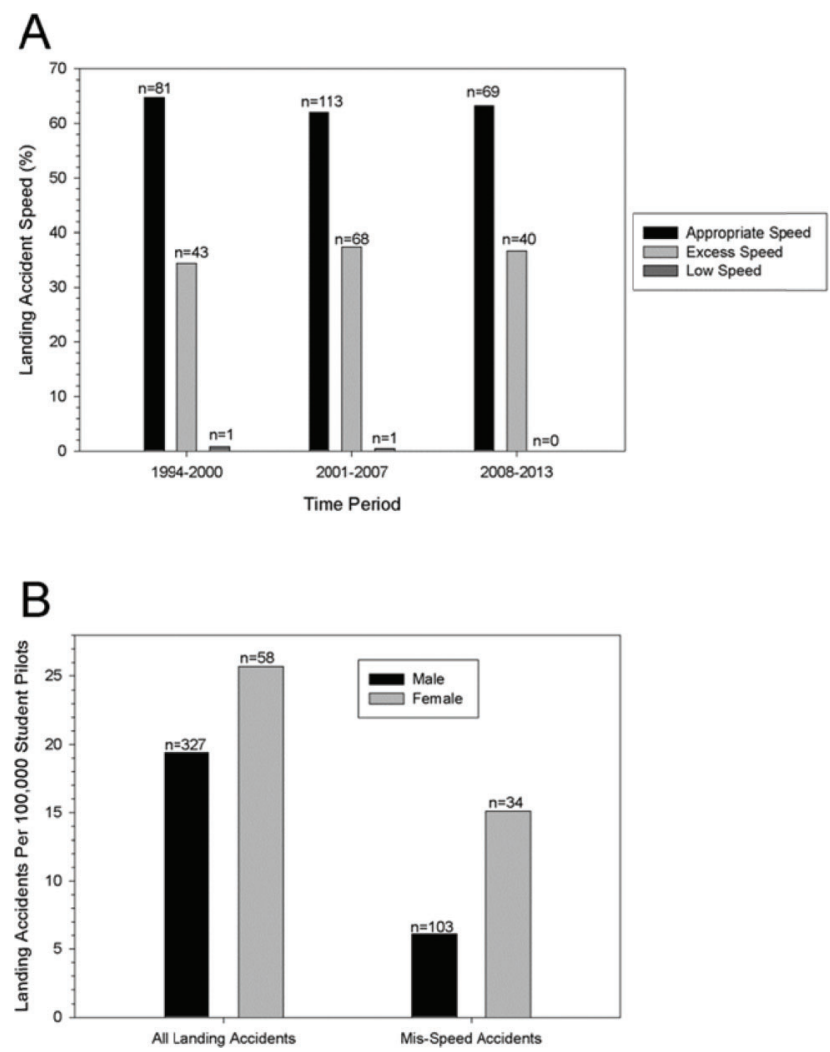

Figure 3. Mis-speed landing accidents. Panel A. Landing accidents were categorized for the indicated period according to landing speed as described in the methods section of this paper. Data are expressed as a percentage of all landing accidents for the corresponding period. A Fisher's Exact test was used to determine if the overall proportions changed between the three time periods. Panel B. Landing accident data categorized by gender were expressed as rates based on the number of male or female student starts. A 2 X2 contingency table (chi-square) was used to determine if the proportions of each gender differed between the "all landing" and mis-speed groups; n, accident count.

\section{Discussion of Results}

For solo students pursuing primary certification the accident rate in a popular training aircraft (Cessna 172) has declined over the past decade, but nevertheless is on par with that of 20 years ago. The fraction of landing accidents, which by far represent the largest category, remains unchanged over the study period whereas (and of concern) mishaps during the takeoff phase of flight have increased. One of the salient findings of this study is that over one-third of landing accidents are related to trainees carrying an excess speed on

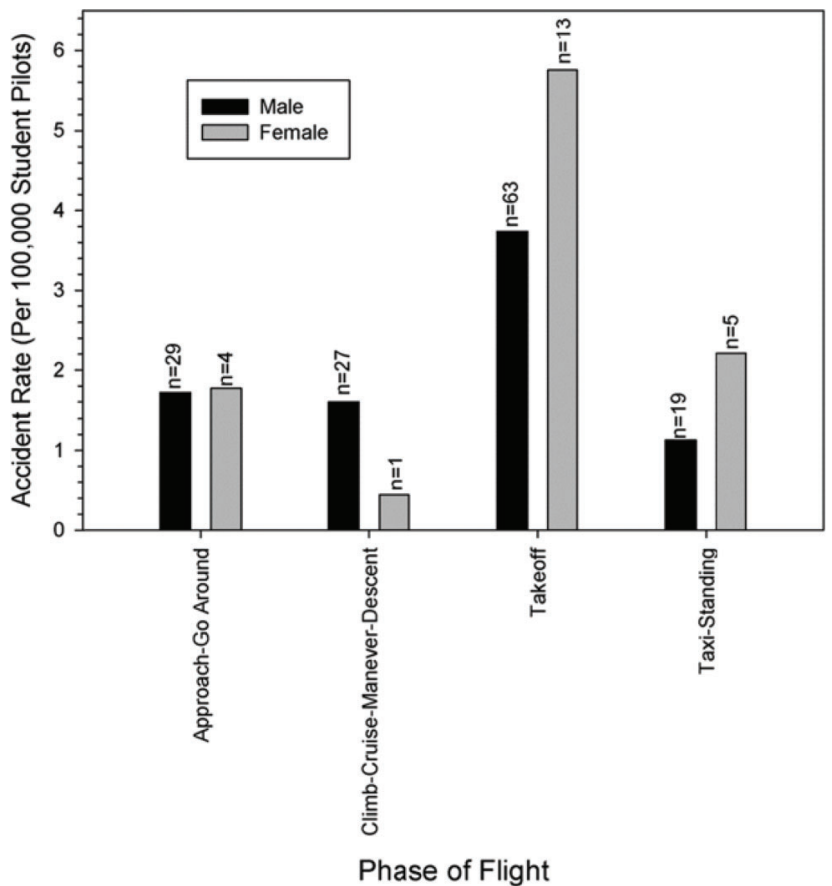

Figure 4. Accident rate based on gender and phase of operation. Accidents, for which phase of flight operation and gender data were available, were expressed as a function of the number of student starts for the indicated gender. A contingency table was used to determine if gender proportions statistically (Fisher's Exact) varied between the various phases of fight; $n$, accident count.

Table 3.

V-ref speed for a Cessna $172 S$ aircraft at a weight below the maximum for which it is certified.

\begin{tabular}{|c|c|c|c|}
\hline & Weight (lbs.) & Vso (kcas) & Vso (kias) \\
\hline Aircraft Basic Empty Weight & $1,642.0$ & & \\
\hline Student Pilot & 181.5 & & \\
\hline $\begin{array}{l}\text { Fuel }(3 \text { hours remaining at } 73 \% \text { power }= \\
\qquad 29.4 \mathrm{~g}+3 \mathrm{~g} \text { unusable })=32.4\end{array}$ & 194.4 & & \\
\hline Total for Solo Flight & $2,017.9$ & & \\
\hline Max Certified Aircraft Weight & $2,550.0$ & & \\
\hline VSO at Max Weight & & 48 & \\
\hline $\begin{array}{l}\text { VSO at Solo Flight Weight: SqRt } \\
\text { (Solo Weight/Max Weight) }\end{array}$ & & 43 & \\
\hline Vref (Solo Flight Weight) $1.3 \mathrm{X}$ VSO & & 56 & 49 \\
\hline
\end{tabular}

The body mass for a student pilot (181.5 lbs.) represented the mathematically weight-adjusted mean of the non-institutionalized United States population age $\geq 16$ years. Basic empty and maximum aircraft weights were per the Cessna C172S POH. Conversion of calibrated (kcas) to indicated airspeed (kias) in knots was by reference to the $\mathrm{C} 172 \mathrm{~S} \mathrm{POH}$. V-ref $=1.3 \mathrm{X} \mathrm{V}_{\mathrm{SO}}$. One gallon of fuel is equivalent to $6 \mathrm{lbs}$. mass. 
final approach, and this rate does not diminish over the twodecade study period. Moreover, females are more likely to be involved in such mis-speed landing accidents than their male counterparts.

Prior studies of instructional flights have yielded conflicting data as to the proportion of accidents in the landing phase. While landing accidents were in the minority (30\%) for one study (Baker et al., 1996), a separate investigation indicated a much higher $(>60 \%)$ percentage (Uitdewilligen $\&$ de Voogt, 2009). Our data clearly align with the latter study. We recognize that the high fraction of landing accidents may be due to the fact that this phase of operation represents one of the most challenging maneuvers for trainees (Uitdewilligen \& de Voogt, 2009) and certified private pilots for that matter (Dambier \& Hinkelbein, 2006). Its mastery is based largely on experience (Hawkins, 1993) and is related to the acquisition of monocular depth perception cues (Langewiesche, 1972), which is a learned process (Benbassat \& Abramson, 2002b; Hawkins, 1993). Hence, it is likely that this maneuver is practiced more often than others required for certification, in turn leading to a higher fraction of accidents. That said, the number of landing mishaps in all studies, including ours, is likely to be conservative. Since most of these mishaps do not result in serious or fatal injuries (which necessitate filing of an accident report), many such events may be classified as incidents if the aircraft is not substantially damaged. Incidents do not require reporting to the NTSB unless categorized as "serious" per 49CFR 830.2 (Electronic Code of Federal Regulation, 2010).

The issue of trainees carrying an excess landing speed merits discussion, especially since airspeed control is one of the most important factors in achieving landing precision (Federal Aviation Administration, 2008). In this regard, the V-ref speed is based on stall speed $\left(=1.3 \mathrm{X} \mathrm{V}_{\mathrm{SO}}\right)$ and the latter is a function of aircraft weight (Clancy, 1978). Indeed, transport category aircraft adjust their landing speed based on aircraft weight (Flight Safety FoundationFlight Safety Digest, 2000). Equally relevant, the FAA advocates lowering landing speed when aircraft weight is reduced from the maximum for which it is certified (Federal Aviation Administration, 2008). The study herein suggests that trainees are either not receiving such instruction and/or not heeding such advice. But why? Multiple possibilities exist. First, most POHs for light aircraft $(<12,500 \mathrm{lbs}$.) state a single approach speed (for a nonshort field landing) predicated on the maximum certified weight. This practice by the manufacturer(s) is consistent with the requirements of 14CFR Part 23 certification for light aircraft. Second, CFIs are not required to cover this element of aerodynamics in the instruction of students pursuing private pilot certification. A third equally plausible reason is that lower speeds lead to less control authority of the primary flight control surfaces with which students are typically uncomfortable.
While landing accidents are partly related to students carrying excess speed, it is by no means the sole cause/ factor. Indeed, there was no evidence of mis-speed for approximately $60 \%$ of the landing accidents in the current study. Prior studies (Benbassat \& Abramson, 2002a; $2002 b$; 2002c) cited poor flaring ability as causal for $18 \%$ of landing accidents and addressed the fact that monocular cues required for depth perception and crucial for flaring are developed through experience. Certainly other factors, such as loss of control due to cross-winds or gusting winds, may also contribute to landing mishaps as reported elsewhere (Baker et al., 1996). However, in the current study we only identified three landing accidents in which gusting wind conditions prevailed.

The higher proportion of mis-speed landing accidents incurred by female students was initially unexpected. Certainly, a prior study reported that males are more likely to be involved in a general aviation accident (across all phases of flight) compared with females ( $\mathrm{Li}$, Baker, Quiang, Grabowski, \& McCarthy, 2005). Moreover, in some neurocognitive tests including that for attention, females outperform males (Gur et al., 2012). However, compared with females, males excel at spatial processing and motor skills (Gur et al., 2012), attributes likely to promote the acquisition of landing skills. Future studies should address whether the preponderance of females involved in mis-speed landings accidents is specific to training or also applicable to certified-female pilots.

The decline in training accident rate over the most recent decade is worthy of discussion. Several elements might contribute to this reduction. First, new strategies in flight training, including scenario-based instruction and the FAAIndustry Training Standards program (Federal Aviation Administration, 2016), may have positively impacted accident rates. It is also possible that more students are undertaking primary instruction in other aircraft, such as light sport airplanes (Electronic Code of Federal Regulation, 2015b). Consistent with this notion, a query of the NTSB database (for aircraft of maximum gross weight of 1,320 lbs. or less — one of the criteria for a light sport aircraft [Electronic Code of Federal Regulation, 2015b]) indicated an increased accident count over the most recent decade. However, it was unclear whether trainees were receiving instruction for a sports pilot or private pilot certification. The decline in accident rate may also be related to the increased proportion of students receiving their training under 14CFR Part 141 versus 14CFR Part 61 (data kindly provided by Carla Colwell, FAA). In contrast with the latter, 14CFR Part 141 provides a more structured training environment with an FAA-approved curriculum (Electronic Code of Federal Regulation, 2016). Stage checks are mandatory and the training program is overseen by the FAA (Electronic Code of Federal Regulation, 2016). Notwithstanding these favorable findings, it should be emphasized that the accident rate, herein, is still on par with that of 20 years ago. 
Our study was not without limitations. First and foremost, it was a retrospective study. Second, for each gender we assumed that training activity was in proportion to the corresponding student population. Third, it is likely that a number of mishaps go unreported, especially where only minor damage resulted. The observed bias in substantially damaged aircraft and the absence of incidents in the study cohort is consistent with this notion. Fourth, our study was confined to training accidents in Cessna 172 aircraft, and different patterns may be evident with other trainers. Finally, differences in age and flight time for student pilots could represent a confounder in our analyses.

In conclusion, the major findings of the current study are the substantial proportion of landing accidents related to an excess landing speed and that females are overrepresented in such mishaps. We believe that landing speed, adjusted for a lower aircraft weight, should be a topic discussed and practiced with primary students. Our findings also have ramifications for training beyond reducing the number of landing accidents. Thus, it is well recognized that landing proficiency has a bearing on applicant self-esteem (Matson, 1973). Accordingly, the positive impact of expedient mastery of this phase of operation could very well reduce time to solo, training cost, and diminish the high (70-80\%) attrition rate of candidates pursuing primary certification (Airplane Owners and Pilot Association, 2010; Matson, 1973).

\section{Acknowledgements}

We are indebted to Brad Wacker, Aviation Safety Information Analysis and Sharing Division FAA, Washington, DC, for providing annual data for student starts. We also express our appreciation to Lance Little, Flight Safety District Office, Houston, TX, for intellectual insights.

\section{References}

Agresti, A. (2012). Categorical data analysis (3rd ed.). Hoboken: Wiley. Airplane Owners and Pilot Association. (2010). The flight training experience-A survey of students pilots and instructors. Retrieved from http://download.aopa.org/epilot/2011/AOPA_Research-The_ Flight_Training_Experience.pdf

Baker, S. P., Lamb, M. W., \& Dodd, R. S. (1996). Crashes of instructional flights. Aviation Space Enviromental Medicine, 67, 105-110.

Benbassat, D., \& Abramson, C. I. (2002a). Comparative approach to pilot error and effective landing flare instructions. International Journal of Comparative Psychology, 15, 249-255.

Benbassat, D., \& Abramson, C. I. (2002b). Landing flare accident reports and pilot perceptions analysis. The International Journal of Aviation Psychology, 12, 137-152.

Benbassat, D., \& Abramson, C. J. (2002c). General aviation landing flare instructions. Journal of Aviation/Aerospace Education and Research, $11,31-38$.

Centers for Disease Control and Prevention. (2015). National health and nutrition examination survey. Retrieved from http://www.cdc.gov/ nchs/nhanes/nhanes_questionnaires.htm
Centers for Disease Control and Prevention. (2016). Specifying weighting parameters. Retrieved from http://www.cdc.gov/nchs/tutorials/ NHANES/SurveyDesign/Weighting/intro.htm

Cessna. (2015). Cessna Skyhawk specifications. Retrieved from http:// cessna.txtav.com/en/single-engine/skyhawk

Clancy, L. J. (1978). Aerodynamics. Harlow: Prentice Hall.

Dambier, M., \& Hinkelbein, J. (2006). Analysis of 2004 German general aviation aircraft accidents according to the HFACS model. Air Medical Journal, 25, 265-269.

DeJohn, C., Webster, N., \& Larcher, J. (2013). U.S. civil aviation in 2012. Aviation Space Enviromental Medicine, 84, 415.

Dobson, A. J., \& Barnett, A. G. (2008). Poisson regression and loglinear models. In An Introduction to Generalized Linear Models, pp. 165-171. Boca Raton: Chapman and Hall/CRC.

Electronic Code of Federal Regulation. (2010). Transportation: Notification and reporting of aircraft accidents or incidents and overdue aircraft, and preservation of aircraft wreckage, mail, cargo and records, 49 CFR 830. (2010). Retrieved from http://www.ecfr.gov/cgi-bin/textidx?tpl=/ecfrbrowse/Title49/49cfr830_main_02.tpl

Electronic Code of Federal Regulation. (2015a). General operating and flight rules. Retrieved from http://www.ecfr.gov/cgi-bin/text-idx?node= $14: 2 \cdot 0 \cdot 1 \cdot 3 \cdot 10$

Electronic Code of Federal Regulation. (2015b). Light-sport aircraft. Retrieved from http://www.ecfr.gov/cgi-bin/text-idx?SID=d6a9d6a4a $1 \mathrm{~d} 815 \mathrm{fd} 6 \mathrm{e} 99 \mathrm{~b} 25 \mathrm{c} 81 \mathrm{~b} 3 \mathrm{f} 455 \& \mathrm{mc}=$ true $\&$ node=se14.1.1_11\&rgn=div8

Electronic Code of Federal Regulation. (2016). Pilot schools. Retrieved from http://www.ecfr.gov/cgi-bin/text-idx?SID=33585c21456a0377 $7231 \mathrm{fb} 01 \mathrm{a} 1261 \mathrm{ef} \& \mathrm{\& c}=$ true \&node $=\mathrm{pt} 14.3 .141 \& \mathrm{rgn}=\mathrm{div} 5$

Federal Aviation Administration. (2008). On landings part II. Oklahoma City: U.S. Department of Transportation. Retrieved from https://www. faasafety.gov/files/gslac/library/documents/2011/Aug/56409/FAA\% 20P-8740-49\%20OnLandingsPart\%20II\%20[hi-res]\%20branded.pdf

Federal Aviation Administration. (2015). General aviation and part 135 activity surveys. Retrieved from http://www.faa.gov/data_research/ aviation_data_statistics/general_aviation

Federal Aviation Administration. (2016). FAA-industry training standards (FITS). Retrieved from https://www.faa.gov/training_testing/training/fits/

Field, A. (2009). Discovering statistics using IBM SPSS statistics. Thousand Oaks: SAGE Publications.

Fielding, E., Lo, A. W., \& Yang, J. H. (2011). The National Transportation Safety Board: A model for systemic risk management. Journal of Investment Management, 9, 17-49.

Flight Safety Foundation-Flight Safety Digest. (2000). ALAR briefing note 8.2-The final approach speed. 163-166.

Gur, R. C., Richard, J., Calkins, M. E., Chiavacci, R., Hansen, J. A., Bilker, W B., . . Gur, R. E. (2012). Age group and sex differences in performance on a computerized neurocognitive battery in children age 8-21. Neuropsychology, 26, 251-265.

Hawkins F. H. (1993). Vision and visual illusions. In M. W. Orlady (Ed.), Human factors in flight (2nd ed.), (pp. 107-130). Burlington, Ashgate Publishing.

Kenny, D. (2014). Accidents during flight instruction: A review. Frederick, MD: Air Safety Institute. Retrieved from https://www.aopa.org/-/media/ files/aopa/home/pilot-resources/safety-and-proficiency/accident-analysis/ special-reports/instructionalaccidentreportfinal.pdf?la=en

Langewiesche, W. (1972). The approach. In Stick and rudder-An explanation of the art of flying (pp. 262-286). New York: McGrawHll Inc.

Li, G., \& Baker, S. P. (2007). Crash risk in general aviation. Journal of American Medical Association, 297, 1596-1598.

Li, G., Baker, S. P., Quiang, Y., Grabowski, J. G., \& McCarthy, M. L. (2005). Driving-while-intoxicated as risk marker for general aviation pilots. Accidents Analysis and Prevention, 37, 179-184.

Matson, W. R. (1973). The comparative effectiveness of a prolonged flare and normal flare on student pilot achievement in the landing 
maneuver and on time to solo. PhD Thesis, Oklahoma State University, Stillwater, OK.

National Transportation Safety Board. (2015a). NTSB accident database. Retrieved from http://app.ntsb.gov/avdata/Access/

National Transportation Safety Board. (2015b). Pilot/operator aircraft accident/incident report. Retrieved from http://www.ntsb.gov/ Documents/6120_1web_nopwx_NotReaderComp. pdf

Uitdewilligen, S., \& de Voogt, A. J. (2009). Aircraft accidents with student pilots flying solo: Analysis of 390 cases. Aviation Space Enviromental Medicine, 80, 803-806.
Douglas Boyd, $\mathrm{PhD}$, is a professor at the University of Texas. He is an active commercial pilot in single- and multiengine aircraft, IFR-certified, and type rated in a Citation 500. His current projects/interests focus on the causes of general aviation accidents.

Peter Dittmer, EdD, is an associate professor at Eastern New Mexico University. He is a certified airline transport pilot and Gold Seal flight instructor who has accrued 8,000 hours of flight instruction over 27 years. He has received the prestigious National Association of Flight Instructors Master Flight Instructor award on three separate occasions. His research interests include aviation safety, human factors, and flight training. 